\title{
Temperature-dependent interactions in the chitosan/cyclosporine A system at liquid-air interface
}

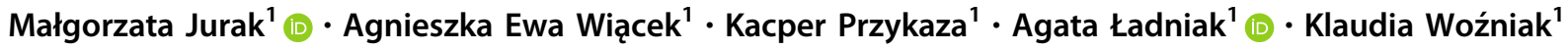

Received: 25 October 2018/ Accepted: 15 March 2019/Published online: 27 March 2019

(C) The Author(s) 2019

\begin{abstract}
Chitosan (Ch) is a polysaccharide mainly used in cosmetics, biotechnology and medicine owing to its biocompatibility, biodegradability and low cytotoxicity. One of the challenges is the development of mechanisms responsible for its action in biomedical applications. In this aspect, it is important to get more profound insight into the chitosan interactions with peptide drugs at the molecular level. The drug of interests was a cyclosporine A (CsA) known for its effective immunosuppressive action against transplant rejection. In this study, the Langmuir technique was used to determine the interactions between $\mathrm{Ch}$ (dissolved in the subphase) and the monomolecular films of CsA spread at the air-chitosan solution interface. The surface pressure versus the area per molecule $(\pi-A)$ measurements of the CsA monolayers on the subphase with or without $\mathrm{Ch}$ was conducted at $20{ }^{\circ} \mathrm{C}$ and $37{ }^{\circ} \mathrm{C}$. The $\mathrm{Ch}$ insertion into the CsA monolayers was monitored by relative changes in the $\frac{\Delta A}{A}$ area and the compression modulus. The findings demonstrate that the presence of $\mathrm{Ch}$ in the subphase provides the CsA monolayer expansion and affects the molecular packing and ordering in the temperaturedependent way. The temperature increase induces conformational changes in the peptide monolayers being a decisive factor which influences the kind and strength of interactions between $\mathrm{Ch}$ and $\mathrm{CsA}$.
\end{abstract}

Keywords Chitosan · Cyclosporine A · Monolayer - Langmuir technique

\section{Introduction}

Synthetic and biological covering materials have been investigated to reduce the thrombosis and restenosis during the implant placement. Chitosan $(\mathrm{Ch})$ has been proposed as a suitable material for implant surface coating for enhancement of biocompatibility to the surrounding tissues $[1,2]$. Since chitosan is obtained by $N$-deacetylation of chitin, the natural polymer present in arthropod and insect exoskeletons, crustacean shells and some fungi cell walls, its biocompatibility is strictly dependent on origin, extraction method and purity [3]. This polysaccharide is composed of $\mathrm{N}$-acetylglucosamine and partially glucosamine units (Fig. 1). Their amount and distribution are responsible for hydrophobic character and interchain

Małgorzata Jurak

malgorzata.jurak@poczta.umcs.lublin.pl

1 Department of Physical Chemistry - Interfacial Phenomena, Faculty of Chemistry, Maria Curie-Skłodowska University, Maria Curie-Skłodowska Sq. 3, 20-031 Lublin, Poland interactions. Various biological and pharmaceutical applications of $\mathrm{Ch}$ are determined by many physicochemical factors, such as molecular weight, degree of deacetylation, degree of substitution, $\mathrm{pH}$ and temperature. Suitable management of these factors allows the $\mathrm{Ch}$ activity to be adjusted to the desired level. In order to improve further biological properties and increase the range of potential applications of $\mathrm{Ch}$ in medicine or pharmacy, many chemical modifications have been made to achieve additional functions, e.g. mucoadhesiveness, antibacterial properties or haemocompatibility [4].

Natural Ch exhibits thrombogenic/haemolytic properties. It promotes blood clotting, the effect being stronger compared to chitin [5]. Ch is characterized by a $\mathrm{pK}_{\mathrm{a}}$ value of approximately 6.5 [6]. When it comes into contact with blood, its positively charged amino groups $\left(-\mathrm{NH}_{3}{ }^{+}\right)$react with negatively charged outer membranes in blood cells causing the platelet activation and thrombus formation. It works not only on platelet aggregation, but it can also aggregate erythrocytes. This feature can be useful in the case of implantology to stop bleeding because chitosan- 

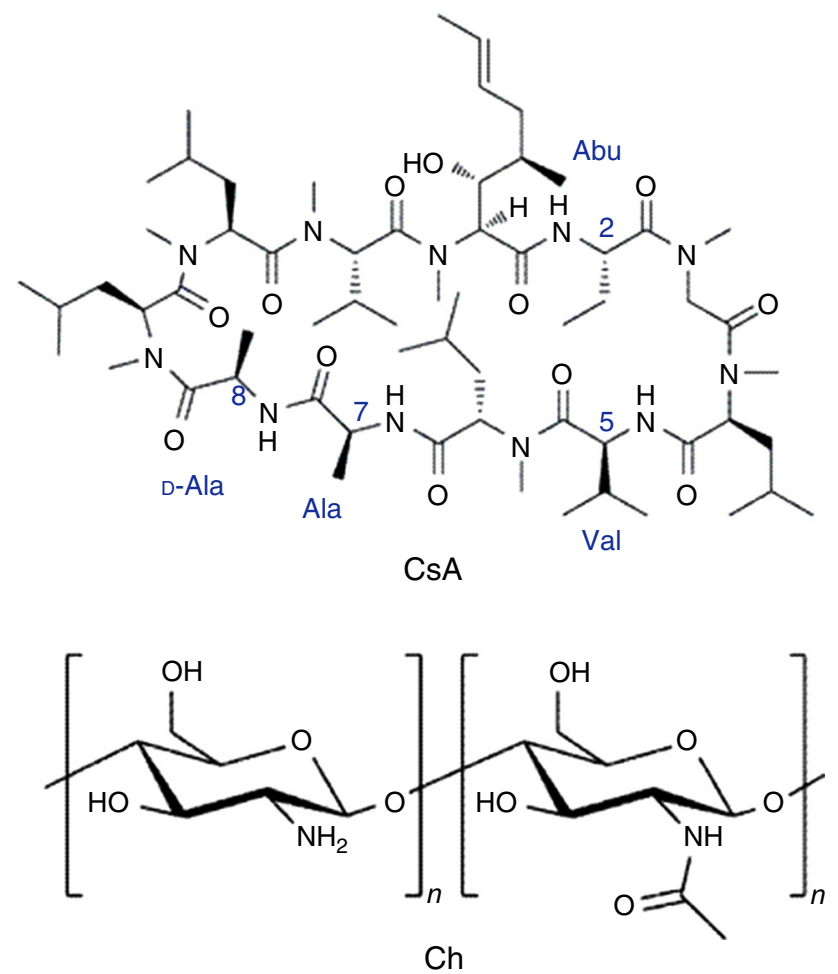

Fig. 1 Structure of cyclosporine A (CsA) with the assigned amino acid residues: Abu-amino butyric acid, Ala—alanine, D-Ala-Dalanine, Val—valine, and structure of chitosan $(\mathrm{Ch})$

based coatings are considered to be the most effective [7]. However, platelet aggregation does not directly reflect blood coagulation. Platelet adhesion, activation of the coagulation pathway and pathogen attachment as a result of protein adsorption are the major unwanted biological responses. Many authors report that $\mathrm{Ch}$ has the ability to activate the blood coagulation system. However, its surface auxiliary modification can result in its anticoagulant properties $[4,8]$. Therefore, the need to exploit the remaining valuable properties of $\mathrm{Ch}$ for biomedical and pharmaceutical applications requires changing its surface properties, more precisely changing or neutralizing its positive charge.

On the other hand, owing to the reactive amino and hydroxyl functional groups within its chemical structure, cationic chitosan can react with peptide-based drugs [9]. This property can be used for the improvement of the delivery system of drugs to the target sites $[10,11]$. One of the drugs which attract the attention of scientists is cyclosporine A (CsA) (Fig. 1).

CsA is an organic compound and, more specifically, a cyclic polypeptide consisting of 11 amino acids with a branched structure. For the first time, it was isolated from the fungus Tolypocladium inflatum. Most of the amide groups contain methyl moieties. Hydrogen bonds originating from the $-\mathrm{NH}$ groups inside the structure determine the intramolecular conformation of CsA. In addition, all methyl amide moieties are present in the trans configuration not taking into account the methyl amino group present in the cis-form between the amino acid residues 9 and 10 [12]. CsA is a neutral, extremely hydrophobic drug used for immunosuppressive therapy in organ transplantation [13]. It exhibits the immunosuppressive activity by inhibiting the selective function of $\mathrm{T}$ lymphocytes, mainly of the helper type $\left(T_{h}\right)$, and reduces production and limits secretion of lymphokines. It also modifies chronic inflammatory processes and finds a possible application as an antimalarial drug; however, the mechanism of its action still has not been explained. In the form of a drug, CsA is used mainly to prevent rejection of skin or transplants of such organs as: heart, kidneys, liver, pancreas, small intestine, lungs. Importantly, it is not lymphocytotoxic and its action is reversible. Among the other immunosuppressants, CsA is distinguished by the fact that it does not inhibit haematopoiesis and does not affect the function of phagocytic cells [14].

CsA is usually administered orally. However after oral dosing, the bioavailability is incomplete $(10-60 \%)$ as a consequence of high hydrophobicity and low aqueous solubility. Thus, transport from the intestinal tract to the blood circulation is limited and depends largely on individuals [15]. Therefore, it is hardly possible to achieve adequate drug level at the sites of transplanted organs. Moreover, acute and chronic nephrotoxicity is a serious side effect associated with the CsA treatment [13].

One of the efficient ways to overcome the above difficulties is encapsulation of CsA in the liposomal carriers or usage of different kinds of nanoparticles (beads or granules) $[13,15]$. This makes possible to reach an elevated drug level at the target sites with a simultaneous decrease in nephrotoxic drug exposure to the kidney. The presence of the surface charge on the liposome membranes or nanoparticles affects greatly the CsA control drug release and distribution to the blood, liver or bone. Particularly, the positively charged particles show prolonged circulation in blood, increased bone uptake and reduced nephrotoxicity as regards free drug [13, 15]. The addition of $\mathrm{Ch}$ biopolymer can be one of the modification ways. The bioavailability of CsA in the oral therapy was found to be by about $73 \%$ higher when positively charged Ch-coated nanoparticles were used [15]. The positive amino groups of Ch carriers strongly interacting with the negatively charged sites on the cell membrane resulted in better permeability and overall bioavailability of the slightly soluble drugs when compared with the neutral or negatively charged ones [15]. A good tolerance of $\mathrm{Ch}$ in vivo could be explained by its superficial interactions with different kinds of cells without inducing a cell membrane damage, for instance, 
the interactions of $\mathrm{Ch}$ with the mucins of the tear film in such a way disturbing viability to a low extent [16].

The uncharged character of CsA, which has no ionizable functional groups in a wide range of $\mathrm{pH}\left(\mathrm{pK}_{\mathrm{a}-}\right.$ =9.45-11.83) $[17,18]$, does not affect the chitosan positive charge but rather its density owing to the lowered Coulombic repulsion. The next step, the formation of stable $\mathrm{Ch} / \mathrm{CsA}$ system by hydrophobic interactions between the hydrocarbon moieties can be facilitated.

Differential scanning calorimetry (DSC) analysis of Ch and CsA can evaluate the physical state of the compounds and the thermal properties which are helpful in the drug formulation [19-22]. Depending on the source, the compounds can exist in different structural forms. For raw $\mathrm{CsA}$, the major characteristic peaks were found at $65^{\circ} \mathrm{C}$ and $132{ }^{\circ} \mathrm{C}$ [19] or $139{ }^{\circ} \mathrm{C}$ [23]. The absence of the melting transitions from a CsA curve in the proliposomal formulations indicated the amorphous nature of CsA. Moreover, the absence of the characteristic DSC peaks corresponding to $\mathrm{CsA}$ confirmed that $\mathrm{CsA}$ was present in the amorphous or noncrystalline form within proliposomes or was amorphously distributed within the polymeric matrix poly(E-caprolactone)-block-poly(ethylene glycol) [23]. The drug as a bulk material was partially amorphous with a certain crystalline fraction [24]. Similarly, Jain et al. [23] reported that cyclosporin A-loaded PLGA nanoparticles showed no melting peak indicating the absence of crystallinity. Hence CsA was amorphously distributed within the polymeric matrix and was not detected on the surface. It might be the reason for a lack of initial drug burst release during the in vitro experiments [23]. On the other hand, the DSC curves for $\mathrm{Ch}$ and $\mathrm{Ch}$ based membranes exhibited the broad endothermic and exothermic peaks in the range of $25-140{ }^{\circ} \mathrm{C}$ and $233-332.5^{\circ} \mathrm{C}[22,25]$. As follows from the above considerations, the phase transitions for both components ( $\mathrm{Ch}$ and CsA) occur at much higher temperatures than the physiological one $\left(37^{\circ} \mathrm{C}\right)$.

As mentioned above, cyclosporine A, a highly hydrophobic polypeptide, has very low water solubility which depends on temperature. According to Molpeceres et al. [26], at $20{ }^{\circ} \mathrm{C}$ CsA solubility is $41.56 \mu \mathrm{g} \mathrm{L}^{-1}$ and dramatically drops to $3.69 \mu \mathrm{g} \mathrm{L}^{-1}$ as temperature rises to $37{ }^{\circ} \mathrm{C}$ (temperature of human body). $\mathrm{Ch}$ can increase the CsA penetration as an effect of screening high hydrophobicity and enhancing drug solubility.

According to the literature, $\mathrm{Ch}$ is thoroughly studied mainly in two biomedical areas. It is used in the cure of wounds, ulcers and burns due to its haemostatic properties. It accelerates wound healing. On the other hand, it is applied as a structural material in the tissue regeneration and restoration owing to its cell affinity and biodegradability. Chitosan has been widely used as a matrix or in combination with other polymers in the drug-release systems, as promising vehicles for drug sustained-release formulations [27].

To increase the therapeutic efficacy of CsA, a new method of drug delivery based on its direct introduction onto the implant surface as a hybrid layer with chitosan can be proposed. The aim of this study was to determine the interactions between the $\mathrm{Ch}$ and $\mathrm{CsA}$ molecules at both temperatures $\left(20^{\circ} \mathrm{C}\right.$ and $\left.37^{\circ} \mathrm{C}\right)$ by means of the Langmuir monolayer technique. The method consisted in spreading of a CsA solution on the subphase with $\mathrm{Ch}$ and compressing of the obtained monolayer to acquire the $\pi$ $A$ isotherms. Their analysis provided information about changes of mean molecular area and phase behaviour affected by the $\mathrm{Ch}$ presence and/or the temperature increase. The temperature-dependent effect was related to fluidity of the $\mathrm{Ch} / \mathrm{CsA}$ mixed systems due to reorganization of the molecular packing of the hydrophobic chains, not to phase transition occurring at much higher temperatures.

Combining positive $\mathrm{Ch}$ and neutral $\mathrm{CsA}$ can decrease the positive charge density of $\mathrm{Ch}$ to gain a less thrombogenic effect, while CsA acquires the support for its effective delivery to increase the pharmacological effect. The gradual release of CsA from the polymer coating should depend on the kind and strength of interactions between the $\mathrm{Ch}$ and drug molecules. In this aspect, the study of interactions between $\mathrm{Ch}$ and CsA at the molecular level can provide improving graft acceptance without impairing immunological defences. Consequently, a simultaneous application of both components gives possibility to form promising systems which contact intimately with the tissue surrounding the biomaterial surfaces. This kind of system ensures the target tissue with long-term drug levels by its gradual release. More profound characteristics allow improving the biocompatibility of the studied systems to prevent the rejection of implant.

\section{Experimental}

\section{Materials}

In our study, following substances were used: chitosan (MW 100,000-300,000, deacetylation degree DD 82\%, provided by Acrōs Organics, Belgium); cyclosporine A (MW 1202.61, 99\%, Alfa Aesar); chloroform (MW 119.38, 98.5\%,); methanol (MW 32.04, 99.8\%); and acetic acid (MW 60.05, 99.5-99.9\%) were purchased from Avantor Performance Materials Poland S.A. and used as solvents. Redistilled water was purified by a Milli-Q system to achieve a resistivity of $18.2 \mathrm{M} \Omega \mathrm{cm}$ and $\mathrm{pH}$ 5.6. This water was used to dilute the acetic acid to the required chitosan solution concentration. 


\section{Preparation of solutions}

The chitosan solution was prepared in the $1 \mathrm{dm}^{3}$ flask by dissolving $100 \mathrm{mg}$ of chitosan in $0.1 \%$ acetic acid. After mixing, the flask was placed in the ultrasonic bath for $20 \mathrm{~min}$ to homogenize the solution. The final concentration of Ch solution was $0.1 \mathrm{mg} \mathrm{mL}^{-1}$ and the measured $\mathrm{pH} 3.1$. It was the same as that used in our previous studies [2, 28] as well as in the measurements conducted by the other authors $[29,30]$. Such concentration was found to be sufficiently high to provoke a possible expansion of the CsA monolayers and to inspect the temperature effects. To prepare the cyclosporine A solution, $1 \mathrm{mg}$ of powder was weighed, placed in the dark glass bottle and dissolved in $1 \mathrm{~mL}$ of chloroform/methanol $4: 1(\mathrm{v} / \mathrm{v})$ to get the final concentration of $1 \mathrm{mg} \mathrm{mL}^{-1}$. This is typical of the Langmuir film measurements. The bottle with the solution was protected with a parafilm to prevent from solvent evaporation and stored in a closed chamber saturated with chloroform.

\section{Methods}

To obtain the surface pressure-area per molecule $(\pi-$ A) isotherms for the cyclosporine A monolayer on the subphase with or without $\mathrm{Ch}$, the Langmuir trough (KSV NIMA, Finland) equipped with symmetric barriers was used. Measurements were taken out at two different temperatures $\left(T_{1}=20^{\circ} \mathrm{C}\right.$ and $\left.T_{2}=37{ }^{\circ} \mathrm{C}\right)$. The constant temperature $\left( \pm 0.1{ }^{\circ} \mathrm{C}\right)$ was kept by the thermostat (Lauda) with the external circulating system. The surface pressure was measured by a platinum Wilhelmy plate with the accuracy $0.1 \mathrm{mN} \mathrm{m}^{-1}$. After thorough cleaning, the Langmuir trough was filled with acetic acid $(0.1 \%)$ or acetic acid with $\mathrm{Ch}\left(0.1 \mathrm{mg} \mathrm{mL}^{-1}\right)$ solution. To purify the subphase surface, an amount of solution was suck out during compression. If the surface pressure did not change more than $0.3 \mathrm{mN} \mathrm{m}^{-1}$, the subphase surface was assumed to be clean. The CsA solution at the concentration of $1 \mathrm{mg} \mathrm{mL}^{-1}$ was added dropwise onto the top of the subphase using the Hamilton microsyringe $(35 \mu \mathrm{L})$. That provided $1.75 \times 10^{16}$ molecules of CsA to form the twodimensional gaseous monolayer on the $\mathrm{Ch}$ subphase. On evaporation of the solvent after $10 \mathrm{~min}$, the monolayers were compressed at a constant rate of $20 \mathrm{~mm} \mathrm{~min}^{-1}$ until their collapse. Simultaneously, the $\pi-A$ isotherms were recorded. Under the above-mentioned conditions, the mutual impact of both components could be easily found out.

\section{Results and discussion}

Due to its hydrophobic character, CsA can form stable Langmuir monolayers at the liquid-air interface. On contrary, Ch used in our study is not able to form such an insoluble type of monomolecular films. Therefore, the mutual interactions between CsA and $\mathrm{Ch}$ at $20{ }^{\circ} \mathrm{C}$ or $37{ }^{\circ} \mathrm{C}$ were evaluated indirectly on the basis of the changes in the area per molecule in the CsA monolayers on the subphase with or without $\mathrm{Ch}$ and the in-plane elasticity (compression modulus) during compression with the Langmuir trough.

The surface pressure-molecular area isotherms for the CsA monolayers in the presence or absence of $\mathrm{Ch}$ at $20{ }^{\circ} \mathrm{C}$ or $37{ }^{\circ} \mathrm{C}$ are presented in Fig. 2. At a given temperature, $\mathrm{Ch}$ induces an expansion of the CsA monolayers which is observed as isotherms shift to the right, i.e. towards larger areas. This behaviour indicates that $\mathrm{Ch}$ penetrates the CsA monolayer. The isotherms of the CsA monolayer at $37^{\circ} \mathrm{C}$ are more inclined than those obtained at $20^{\circ} \mathrm{C}$, thus proving a more fluid or less rigid state of monolayer.

Simultaneously, the surface pressure of the monolayer collapse increases (Table 1). The monolayer collapse was determined via extrapolation of the point of intersection lines above and below the inflection of the $\pi-A$ isotherm. The increase in pressure collapse suggests higher monolayer stability due to the favourable Ch-CsA interactions. The collapse point reported in the literature for the CsA monolayer on water is $27 \mathrm{mN} \mathrm{m}^{-1}$ [31]. Accordingly, one can claim that the AA subphase affects the surface elasticity, and consequently, the collapse pressure decreases to $17.7 \mathrm{mN} \mathrm{m}^{-1}$. Moreover, to evaluate the expansion of the monolayer directly from the $\pi-A$ isotherms, the lift-off area $\left(A_{0}\right)$ and the limiting area $\left(A_{\mathrm{lim}}\right)$ were determined. The $A_{0}$

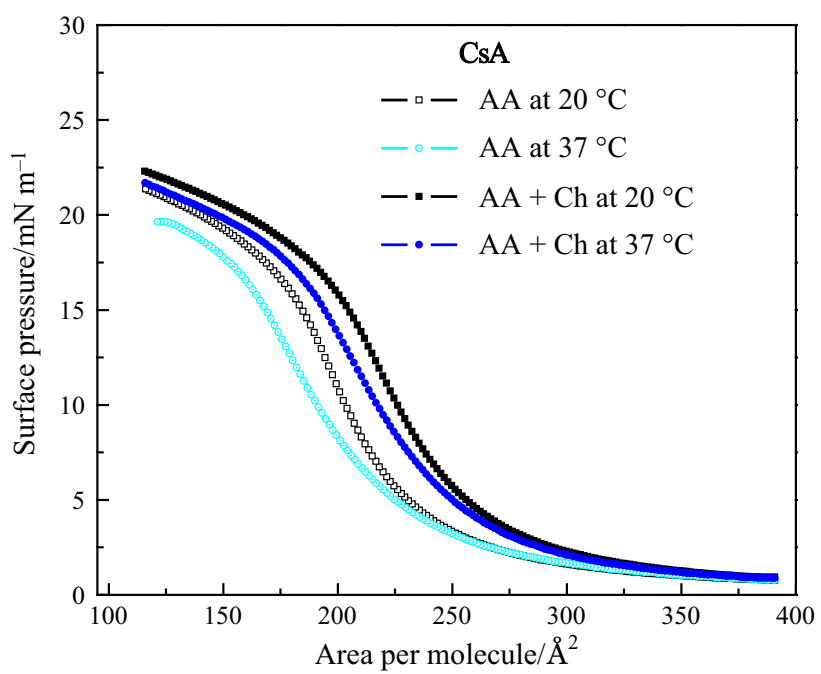

Fig. 2 Surface pressure-area $(\pi-A)$ isotherms for the CsA monolayers on acetic acid (AA) or chitosan in the acetic acid (AA $+\mathrm{Ch}$ ) subphase at $20{ }^{\circ} \mathrm{C}$ or $37^{\circ} \mathrm{C}$ 
Table 1 Changes of the surface pressure collapse $\left(\pi_{\text {coll }}\right)$, lift-off $\left(A_{0}\right)$ and limiting $\left(A_{\text {lim }}\right)$ area per molecule in the CsA monolayers on the subphase with or without $\mathrm{Ch}$ at $20^{\circ} \mathrm{C}$ and $37^{\circ} \mathrm{C}$

\begin{tabular}{llll}
\hline CsA & $\pi_{\text {coll }} / \mathrm{mN} \mathrm{m}^{-1}$ & $A_{0} / \AA^{2}$ & $A_{\text {lim }} / \AA^{2}$ \\
\hline AA at $20{ }^{\circ} \mathrm{C}$ & 17.7 & 350.9 & 243.4 \\
$\mathrm{AA}$ at $37^{\circ} \mathrm{C}$ & 17.6 & 355.7 & 235.5 \\
$\mathrm{AA}+\mathrm{Ch}$ at $20{ }^{\circ} \mathrm{C}$ & 18.3 & 374.2 & 267.6 \\
$\mathrm{AA}+\mathrm{Ch}$ at $37{ }^{\circ} \mathrm{C}$ & 18.1 & 372.2 & 260.6 \\
\hline
\end{tabular}

parameter indicates the area at which the transition from the gas into liquid-expanded phase takes place. Its value is within 350.9-374.2 $\AA^{2}$ (Table 1). In the presence of $\mathrm{Ch}, A_{0}$ increases by $23.3 \AA^{2}$ and $16.5 \AA^{2}$ at $20{ }^{\circ} \mathrm{C}$ and $37{ }^{\circ} \mathrm{C}$, respectively (Table 1 ). The $A_{\text {lim }}$ parameter was determined by extrapolating the linear part of isotherm to the zero surface pressure. It denotes the area occupied by a molecule in the most compact monolayer. The obtained values are listed in Table 1 and are in fairly good agreement with the range of 230-260 $\AA^{2}$ reported by Fahr and Reiter [32]. In the presence of $\mathrm{Ch}$, the increase in this parameter by $24.2 \AA^{2}$ and $25.1 \AA^{2}$ at $20{ }^{\circ} \mathrm{C}$ and $37{ }^{\circ} \mathrm{C}$, respectively, was observed. From these results, it can be concluded that $\mathrm{Ch}$ affects the expansion of CsA monolayers due to their penetration, but a slightly more evident effect of temperature on the CsA monolayers is observed in the absence of Ch.

To determine the physical state of the investigated films and to obtain information on the packing and ordering of molecules in the monolayers, the compression modulus values were calculated according to the equation [14]:

$C_{\mathrm{s}}^{-1}=-A\left(\frac{\mathrm{d} \pi}{\mathrm{d} A}\right)_{\mathrm{T}, \mathrm{n}}$

where $A$ denotes the area per molecule at a given surface pressure $\pi$.

The obtained results of $C_{\mathrm{s}}^{-1}$ as a function of surface pressure and area per molecule are presented in Figs. 3 and 4 , respectively. Moreover, the maximal values of $C_{\mathrm{s}}^{-1}$ are listed in Table 2 along with the accompanying surface pressure and area per molecule parameters. All values are lower than $100 \mathrm{mN} \mathrm{m}^{-1}$ which, according to Davies and Rideal [33], indicates the liquid-expanded type of monolayers. The maxima appear at closely the same surface pressure of $11-12 \mathrm{mN} \mathrm{m}^{-1}$, while the molecular areas are significantly different (Table 2). It is worth mentioning that the theoretical cross-section area of CsA obtained based on the molecular modelling data is $230 \AA^{2}$ [32]. The same value of the mean molecular area at maximal $C_{\mathrm{s}}^{-1}$ for the CsA monolayer on water was determined by Dynarowicz et al. [31].

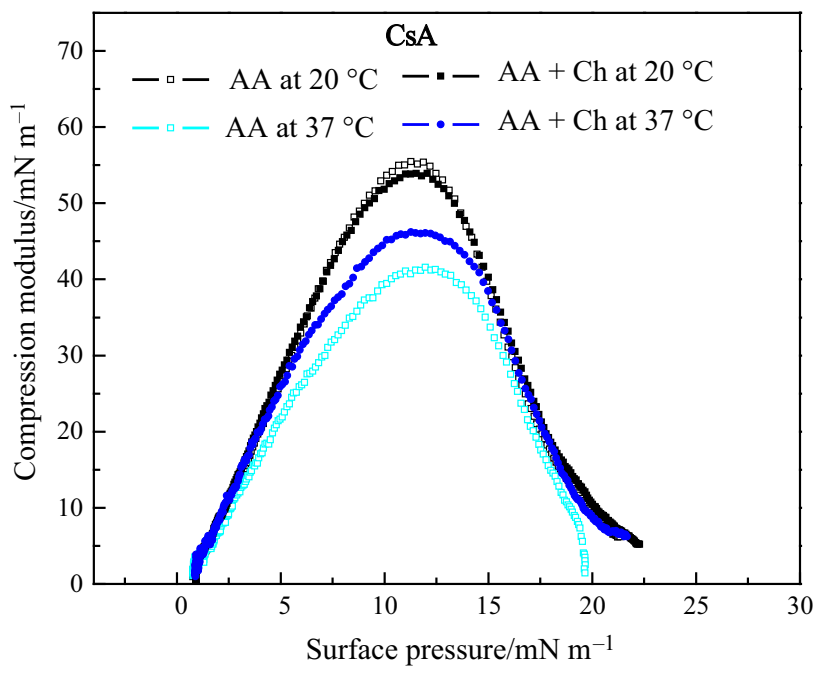

Fig. 3 Compression modulus as a function of surface pressure for the CsA monolayers on acetic acid (AA) or chitosan in the acetic acid $(\mathrm{AA}+\mathrm{Ch})$ subphase at $20^{\circ} \mathrm{C}$ or $37^{\circ} \mathrm{C}$

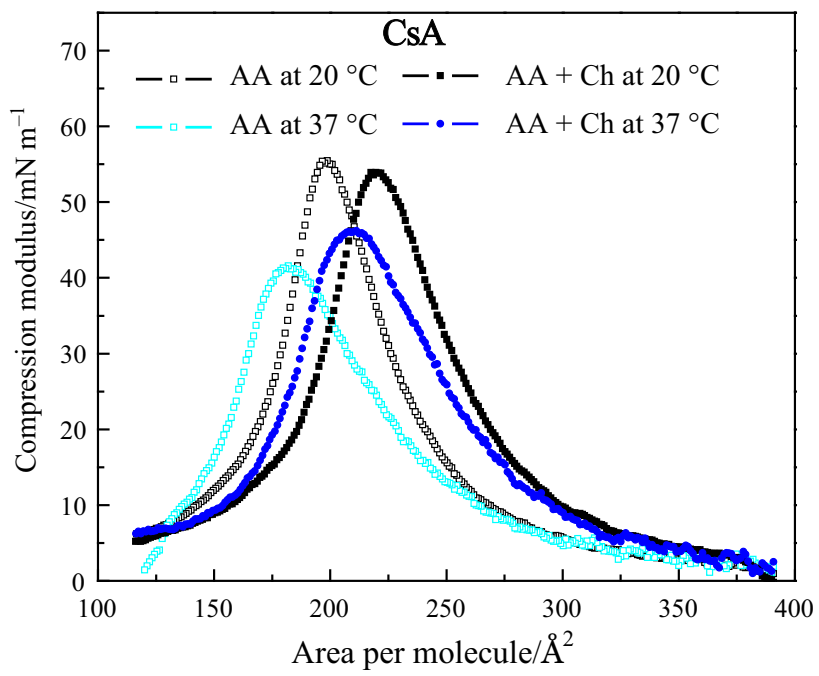

Fig. 4 Compression modulus as a function of area per molecule for the CsA monolayers on acetic acid (AA) or chitosan in the acetic acid $(\mathrm{AA}+\mathrm{Ch})$ subphase at $20^{\circ} \mathrm{C}$ or $37^{\circ} \mathrm{C}$

Table 2 Maximal compression modulus for the CsA monolayers on acetic acid (AA) or chitosan in the acetic acid (AA $+\mathrm{Ch})$ subphase at $20{ }^{\circ} \mathrm{C}$ or $37^{\circ} \mathrm{C}$ along with the accompanying surface pressure $(\pi)$ and the area per molecule $(A)$

\begin{tabular}{llll}
\hline $\mathrm{CsA}$ & $C_{\mathrm{s}}^{-1} \mathrm{max} / \mathrm{mN} \mathrm{m}^{-1}$ & $\pi / \mathrm{mN} \mathrm{m}^{-1}$ & $A / \AA^{2}$ \\
\hline $\mathrm{AA}$ at $20^{\circ} \mathrm{C}$ & 55.5 & 11.3 & 198.7 \\
$\mathrm{AA}$ at $37^{\circ} \mathrm{C}$ & 41.6 & 12.0 & 182.0 \\
$\mathrm{AA}+\mathrm{Ch}$ at $20^{\circ} \mathrm{C}$ & 54.0 & 11.4 & 220.2 \\
$\mathrm{AA}+\mathrm{Ch}$ at $37{ }^{\circ} \mathrm{C}$ & 46.3 & 11.6 & 209.7 \\
\hline
\end{tabular}


In our case, the $A$ values corresponding to $C_{\mathrm{s}}^{-1} \max$ are lower (Table 2) probably due to the conformational changes of CsA molecules induced by the subphase composition and temperature. Cámara et al. [6] investigated the effect of $\mathrm{Ch}$ on the distearoylphosphatidic acid (DSPA) monolayer. They found that as the amount of $\mathrm{Ch}$ in the subphase increased, the molecular area increased and the monolayer compressibility modulus decreased reaching the values typical of liquid-expanded state. The observed behaviour was explained as confirmation of the $\mathrm{Ch}$ presence at the air-liquid interface resulting in significant changes in the monolayer state due to the interactions of $\mathrm{Ch}$ molecules with the hydrophilic parts of DSPA. Moreover, in this case the temperature impact was also very significant. As the temperature increased from 10 to $50{ }^{\circ} \mathrm{C}$ (step $10{ }^{\circ} \mathrm{C}$ ), the isotherms were distorted and gradually shifted to the larger area per molecule. Thus, the molecular movement of $\mathrm{Ch}$ and DSPA was enhanced. The authors explain this fact by stretching of the polymer and penetration of $\mathrm{Ch}$ molecules into the monolayer.

In order to illustrate more precisely the effect of $\mathrm{Ch}$ and temperature on the mean molecular area in the peptide monolayers, the relative change in the area, i.e. $\frac{\Delta A}{A} / \%$, was calculated. This parameter was used for monitoring the degree of $\mathrm{Ch}$ insertion into the CsA monolayers. The values determined at the same temperature $\left(20^{\circ} \mathrm{C}\right.$ or $\left.37^{\circ} \mathrm{C}\right)$ and at the given surface pressure $\left(5-15 \mathrm{mN} \mathrm{m}^{-1}\right)$ are listed in Table 3.

Comparison of the area shows varying results depending on the $\mathrm{Ch}$ presence and temperature. At $20{ }^{\circ} \mathrm{C}$, Ch induces an increase in the area of around $11 \%$ regardless of surface pressure. However, a larger increase in the area (up to $15 \%$ ) occurs at $37{ }^{\circ} \mathrm{C}$ due to a more expanded and disordered state of created monolayers. These changes are revealed in lower values of $C_{\mathrm{s}}^{-1}$ (Figs. 3, 4). This area enhancement can be interpreted as the progressive penetration of $\mathrm{Ch}$ into the CsA monolayer owing to the hydrophobic interactions and/or hydrogen bonding.

Surprisingly, the temperature increase from 20 to $37^{\circ} \mathrm{C}$ causes the decrease in the area so that the $\frac{\Delta A}{A}$ parameter has negative values. These values are very similar to the systems with or without $\mathrm{Ch}$ only at $5 \mathrm{mN} \mathrm{m}^{-1}$. At higher pressures $\left(10 \mathrm{mN} \mathrm{m}^{-1}\right.$ and $\left.15 \mathrm{mN} \mathrm{m}^{-1}\right)$, the $\frac{\Delta A}{A}$ values are differentiated and they appear to be lower by $2.2-3.6 \%$ in the presence of $\mathrm{Ch}$. It can be assumed that reorganization of the molecular packing provides the mean area contraction.

To understand these findings better, it should be emphasized that the aqueous solubility of CsA is temperature dependent. As mentioned earlier, it decreases with the increasing temperature $\left(41.56 \mu \mathrm{g} \mathrm{mL}^{-1}\right.$ at $20{ }^{\circ} \mathrm{C}$ and $3.69 \mu \mathrm{g} \mathrm{mL}^{-1}$ at $37{ }^{\circ} \mathrm{C}$ ) [26]. Temperature-dependent behaviour of CsA is explained by the negative values of heat solution at low temperatures $\left(10-30^{\circ} \mathrm{C}\right)$ which indicates that the dissolution process is exothermic; however, at the higher temperature, $37{ }^{\circ} \mathrm{C}$ positive values of heat solution appear and gradually grow till the temperature reaches $50{ }^{\circ} \mathrm{C}$ [26]. The low aqueous solubility is entropy controlled since the enthalpy change is favourable below $37{ }^{\circ} \mathrm{C}$. Ross and Subramanian [34] proved that as the temperature rises, the hydrophobic solvation decreases. This can provide explanation of the differences in the heat of solution in the aqueous phase from the exothermic to near zero values for the state above the physiological temperature of $37{ }^{\circ} \mathrm{C}$ [34]. Moreover, owing to lacks of ionizable functional groups, solubility of CsA is not sensitive to $\mathrm{pH}$ changes [35]. In the other words, dissolution is an exothermic process driven enthalpically due to the decrease in CsA entropy in solution. This is strictly associated with the temperature-dependent conformational changes of CsA. At higher temperatures, the intramolecular $\mathrm{H}$-bonds formed via the $-\mathrm{NH}$ groups of amino acids (Abu2, Ala-7, Val-5 and D-Ala-8, Fig. 1) are sufficiently strong to produce a more rigid configuration [36]. Such behaviour is due to loss of hydration water which causes conformational change of the D-Ala-8 amino acid residue $[37,38]$. It is likely that at $37^{\circ} \mathrm{C} \mathrm{CsA}$ (due to stronger intramolecular hydrogen bonds) exhibits lower capability of forming intermolecular hydrogen bonds with $\mathrm{Ch}$. As a result of conformational changes at a higher temperature, reduction in the mean area of CsA takes place (Table 3). Its less negative changes on the $\mathrm{Ch}$ subphase indicate penetration of $\mathrm{Ch}$ between the CsA molecules which induces contraction due to mutual hydrophobic interactions. They seem to be the main factor determining the interfacial behaviour in the $\mathrm{CsA}-\mathrm{Ch}$ system at $37^{\circ} \mathrm{C}$. On the other hand, hydrogen bonds and/or electrostatic forces make a contribution at lower temperature.

In our studies, the degree of deacetylation (DD) of $\mathrm{Ch}$ is about $82 \%$. Thus, both the acetylated and deacetylated units of $\mathrm{Ch}$ with the proton donor/acceptor groups are able to participate in hydrogen bonding [39] with the polar head groups of CsA submerged in the subphase, while the hydrophobic side chains are arranged in a vertical position towards the air [40]. Since chitosan is the only soluble component in the proton rich subphase due to the presence of amino groups in its molecule, each experiment was conducted with the addition of acid to obtain positively charged chitosan molecules with the $-\mathrm{NH}_{3}^{+}$groups. This can suggest that despite van der Waals hydrophobic interactions, strong electrostatic forces can occur. Krajewska et al. postulated that $\mathrm{Ch}$ can interact with the lipid cell membrane due to both electrostatic and nonelectrostatic contributions [29, 30]. The effect is stronger 
Table 3 Changes of the area per molecule in the CsA monolayers on the subphase with $\mathrm{Ch}\left(A^{\prime}\right)$ or without $\mathrm{Ch}(A)$ marked $\mathbf{I}$; changes of the area per molecule in the monolayers at $20^{\circ} \mathrm{C}(A)$ or $37^{\circ} \mathrm{C}\left(A^{\prime}\right)$ marked II

\begin{tabular}{|c|c|c|c|c|c|}
\hline I & $\pi / \mathrm{mN} \mathrm{m}^{-1}$ & $\mathrm{AA}$ at $20^{\circ} \mathrm{C}, A / \AA^{2}$ & $\mathrm{AA}+\mathrm{Ch}$ at $20^{\circ} \mathrm{C}, A^{\prime} / \AA^{2}$ & $A^{\prime}-A=\Delta A / \AA^{2}$ & $\frac{\Delta A}{A} \cdot 100 / \%$ \\
\hline & 5 & 230.3 & 255.9 & 25.6 & 11.1 \\
\hline & 10 & 203.6 & 226.1 & 22.5 & 11.1 \\
\hline & 15 & 184.3 & 204.8 & 20.5 & 11.1 \\
\hline & $\pi / \mathrm{mN} \mathrm{m}^{-1}$ & AA at $37^{\circ} \mathrm{C}, A / \AA^{2}$ & $\mathrm{AA}+\mathrm{Ch}$ at $37^{\circ} \mathrm{C}, \mathrm{A}^{\prime} / \AA^{2}$ & $A^{\prime}-A=\Delta A / \AA^{2}$ & $\frac{\Delta A}{A} \cdot 100 / \%$ \\
\hline & 5 & 224.7 & 249.7 & 25.0 & 11.1 \\
\hline & 10 & 191.1 & 217.2 & 26.1 & 13.7 \\
\hline & 15 & 168.2 & 194.3 & 26.1 & 15.5 \\
\hline II & $\pi / \mathrm{mN} \mathrm{m}^{-1}$ & $\mathrm{AA}$ at $20^{\circ} \mathrm{C}, A / \AA^{2}$ & AA at $37{ }^{\circ} \mathrm{C}, A^{\prime} / \AA^{2}$ & $A^{\prime}-A=\Delta A / \AA^{2}$ & $\frac{\Delta A}{A} \cdot 100 / \%$ \\
\hline & 5 & 230.3 & 224.7 & -5.6 & -2.4 \\
\hline & 10 & 203.6 & 191.1 & -12.5 & -6.1 \\
\hline & 15 & 184.3 & 168.2 & -16.1 & -8.7 \\
\hline & $\pi / \mathrm{mN} \mathrm{m}^{-1}$ & $\mathrm{AA}+\mathrm{Ch}$ at $20^{\circ} \mathrm{C}, A / \AA^{2}$ & $\mathrm{AA}+\mathrm{Ch}$ at $37{ }^{\circ} \mathrm{C}, A^{\prime} / \AA^{2}$ & $A^{\prime}-A=\Delta A / \AA^{2}$ & $\frac{\Delta A}{A} \cdot 100 / \%$ \\
\hline & 5 & 255.9 & 249.7 & -6.2 & -2.4 \\
\hline & 10 & 226.1 & 217.2 & -8.9 & -3.9 \\
\hline & 15 & 204.8 & 194.3 & -10.5 & -5.1 \\
\hline
\end{tabular}

with the increasing temperature. These interactions are facilitated by $\mathrm{Ch}$ penetration and the insertion into the monolayer to some extent. At small areas per molecule, i.e. at higher surface pressure, $\mathrm{Ch}$ can be partially expelled from the air-solution interface to form a subsurface interacting with the polar parts of peptide [41]. This cannot be excluded in our case.

Besides, the addition of $\mathrm{Ch}$ into the subphase exerts little fluidization on the $\mathrm{CsA}$ monolayer at $20{ }^{\circ} \mathrm{C}$; however, at the higher temperature $37^{\circ} \mathrm{C}$, the effect is opposite, i.e. Ch makes the CsA monolayer more rigid (Figs. 3, 4 and Table 2). At that time, the CsA molecules can adopt more vertical orientation facilitating incorporation of $\mathrm{Ch}$ and thus interactions with the attractive van der Waals forces. Moreover, as temperature increases, $\mathrm{Ch}$ is more flexible [6] and inserts between the monolayer molecules readily causing an increase in molecular area (Table 3). The higher value of $\frac{\Delta A}{A}$ parameter is observed at $37{ }^{\circ} \mathrm{C}$. On the other hand, a higher temperature induces also dissociation of $\mathrm{Ch}$ amine groups decreasing the positive charge of polymer which results in the contraction of its molecules [6]. In turn, the altering surface charge density affects the arrangement of water molecules near the interface [42]. Such conditions allow for both superficial interactions by hydrogen bonding and those between the hydrophobic $\mathrm{Ch}$ backbone and the hydrocarbon chains of CsA due to the Lifshitz-van der Waals interactions (including London dispersion forces, Keesom dipole-dipole forces and
Debye dipole induced-dipole forces). That is why the molecular area of CsA is smaller at $37{ }^{\circ} \mathrm{C}$, but on the $\mathrm{Ch}$ subphase the monolayer is more tightly packed than without $\mathrm{Ch}$ at the same temperature (Tables 2 and 3).

\section{Conclusions}

It was observed that the presence of $\mathrm{Ch}$ in the subphase modulates properties of the Langmuir monolayers of CsA causing changes in the mean molecular areas and elasticity. On the Ch-containing subphases, the monolayers are more expanded at both $20{ }^{\circ} \mathrm{C}$ and $37{ }^{\circ} \mathrm{C}$. It is likely that $\mathrm{Ch}$ is located between the peptide molecules, interacting by hydrogen bonding, hydrophobic and/or electrostatic forces. It was proved that temperature is an essential factor which affects the strength of these interactions. In our opinion, at $37{ }^{\circ} \mathrm{C} \mathrm{Ch}$ can interact with CsA mainly through the Lifshitz-van der Waals interactions. Intermolecular hydrogen bonds from the $-\mathrm{NH}$ groups of $\mathrm{CsA}$ are stronger with the decreasing temperature, thus increasing CsA solubility. On the basis of the obtained results, we hope that these studies will be helpful to understand better the complicated mechanism of $\mathrm{Ch}-\mathrm{CsA}$ interactions in the human body taking into account the drug delivery systems. 
Open Access This article is distributed under the terms of the Creative Commons Attribution 4.0 International License (http://creative commons.org/licenses/by/4.0/), which permits unrestricted use, distribution, and reproduction in any medium, provided you give appropriate credit to the original author(s) and the source, provide a link to the Creative Commons license, and indicate if changes were made.

\section{References}

1. Farhatnia Y, Tan A, Motiwala A, Cousins BG, Seifalian AM. Evolution of covered stents in the contemporary era: clinical application, materials and manufacturing strategies using nanotechnology. Biotechnol Adv. 2013;31:524-42.

2. Jurak M, Wiącek AE, Mroczka R, Łopucki R. Chitosan/phospholipid coated polyethylene terephthalate (PET) polymer surfaces activated by air plasma. Colloids Surf A Physicochem Eng Asp. 2017;532:155-64.

3. Kaur S, Dhillon GS. The versatile biopolymer chitosan: potential sources, evaluation of extraction methods and applications. Crit Rev Microbiol. 2014;40:155-75.

4. Tripathi K, Singh A. Chitin, chitosan and their pharmacological activities: a review. Int J Pharm Sci Res. 2018;9:2626-35.

5. Okamoto Y, Yano R, Miyatake K, Tomohiro I, Shigemasa Y, Minami S. Effects of chitin and chitosan on blood coagulation. Carbohydr Polym. 2003;53:337-42.

6. Cámara CI, Rivaa JS, Juáreza AV, Yudia LM. Interaction of chitosan and self-assembled distearoylphosphatidic acid molecules at liquid/liquid and air/water interfaces. Effect of temperature. J Phys Org Chem. 2016;29:672-81.

7. Bano I, Arshad M, Yasin T, Ghauri MA, Younus M. Chitosan: a potential biopolymer for wound management. Int J Biol Macromol. 2017;102:380-3.

8. Li Z, Hu W, Zhao Y, Ren L, Yuan X. Integrated antibacterial and antifouling surfaces via cross-linking chitosan-g-eugenol/zwitterionic copolymer on electrospun-membranes. Colloids Surf B Biointerfaces. 2018;169:151-9.

9. Hu B, Wang SS, Li J, Zeng XX, Huang QR. Assembly of bioactive peptide-chitosan nanocomplexes. J Phys Chem B. 2011;115:7515-23.

10. De Campos AM, Sánchez A, Alonso MJ. Chitosan nanoparticles: a new vehicle for the improvement of the delivery of groups to the ocular surface. Application to cyclosporine A. Int J Pharm. 2001;224:159-68.

11. Başaran E, Yenilmez E, Berkman MS, Büyükköroğlu G, Yazan Y. Chitosan nanoparticles for ocular delivery of cyclosporine. J Microencapsul. 2014;31:49-57.

12. Soderlund T, Lehtonen JYA, Kinnunen PKJ. Interactions of cyclosporin A with phospholipid membranes: effect of cholesterol. Mol Pharmacol. 1999;55:32-8.

13. Arulsudar N, Subramanian N, Mishra P, Sharma RK, Murthy RSR. Preparation, characterization and biodistribution of ${ }^{99 \mathrm{~m}} \mathrm{Tc}-$ labeled liposome encapsulated cyclosporine. J Drug Target. 2003;11:187-96.

14. Kallen J, Mikol V, Quesniaux VFJ, Walkinshaw MD, SchneiderScherzer E, Schorgendorfer K, Weber G, Fliri HG. Cyclosporins: recent developments in biosynthesis, pharmacology and biology, and clinical applications. In: Rehm HJ, Reed G, Puhler A, Von Dohren H, editors. Biotechnology, a multivolume comprehensive treatise, vol. 7. Weinheim: VCH Press; 1997. p. 535-91.

15. El-Shabouri MH. Positively charged nanoparticles for improving the oral bioavailability of cyclosporine-A. Int $\mathrm{J}$ Pharm. 2002;249:101-8.
16. Hermans K, Van den Plas D, Everaert A, Weyenberg W, Ludwig A. Full factorial design, physicochemical characterisation and biological assessment of cyclosporine a loaded cationic nanoparticles. Eur J Pharm Biopharm. 2012;82:27-35.

17. https://wiki.toxbank.net/wiki/Cyclosporin_A. Accessed 1 Feb 2019.

18. https://www.drugbank.ca/drugs/DB00091. Accessed 1 Feb 2019.

19. Karn PR, Jin S-E, Lee BJ, Sun BK, Kim J-H Sung, Hwang S-J. Preparation and evaluation of cyclosporin A-containing proliposomes: a comparison of the supercritical antisolvent process with the conventional film method. Int J Nanomed. 2014;9:5079-91.

20. Lino MES, Ruela ALM, Trevisan MG, Pereira GR. Influence of hydration and crosslinking in transdermal delivery of nicotine from chitosan-based gels by thermal analysis. J Therm Anal Calorim. 2017;130:1455-61.

21. Fasihi Z, Zakeri-Milani P, Nokhodchi A, Akbari J, BarzegarJalali M, Loebenberg R, Valizadeh H. Thermodynamic approaches for the prediction of oral drug absorption. J Therm Anal Calorim. 2017;130:1371-82.

22. Sette-de-Souza PH, Medeiros FD, Santana CP, Araújo CartaxoFurtado NAO, Macêdo RO, Medeiros ACD. Thermal decomposition profile of chitosan microparticles produced with Schinopsis brasiliensis Engler extract. J Therm Anal Calorim. 2018;131:829-34.

23. Jain S, Mittal A, Jain AK. Enhanced topical delivery of cyclosporine-A using PLGA nanoparticles as carrier. Curr Nanosci. 2011;7:524-30.

24. Müller RH, Runge SA, Ravelli V, Thünemann Mehnert W, Souto EB. Cyclosporine-loaded solid lipid nanoparticles (SLN): druglipid physicochemical interactions and characterization of drug incorporation. Eur J Pharm Biopharm. 2008;68:535-44.

25. Behera SS, Das U, Kumar A, Bissoyi A, Singh AK. Chitosan/ $\mathrm{TiO}_{2}$ composite membrane improves proliferation and survival of L929 fibroblast cells: application in wound dressing and skin regeneration. Int J Biol Macromol. 2017;98:329-40.

26. Molpeceres J, Guzmfin M, Bustamante P, del Rosario Aberturas M. Exothermic-endothermic heat of solution shift of cyclosporine A related to poloxamer 188 behavior in aqueous solutions. Int $\mathbf{J}$ Pharm. 1996;130:75-81.

27. Carreira AS, Gonçalves FAMM, Mendonça Gil MH, Coelho JFJ. Temperature and $\mathrm{pH}$ responsive polymers based on chitosan: applications and new graft copolymerization strategies based on living radical polymerization. Carbohydr Polym. 2010;80:618-30.

28. Wiącek AE, Terpiłowski K, Jurak M, Worzakowska M. Lowtemperature air plasma modification of chitosan-coated PEEK biomaterials. PolymTest. 2016;50:325-34.

29. Krajewska B, Wydro P, Kyziol A. Chitosan as a subphase disturbant of membrane lipid monolayers. The effect of temperature at varying pH: I. DPPG. Colloids Surf A Physicochem Eng Asp. 2013;434:349-58.

30. Krajewska B, Wydro P, Kyziol A. Chitosan as a subphase disturbant of membrane lipid monolayers. The effect of temperature at varying pH: II. DPPC and cholesterol. Colloids Surf A Physicochem Eng Asp. 2013;434:359-64.

31. Dynarowicz-Łątka P, Wnętrzak A, Makyła-Juzak K. Cyclosporin A in membrane lipids environment: implications for antimalarial activity of the drug-the Langmuir monolayer studies. J Membrane Biol. 2015;248:1021-32.

32. Fahr A, Reiter G. Biophysical characterization of liposomal delivery systems for lipophilic drugs: cyclosporine A as an example. Cell Mol Biol Lett. 1999;4:611-23.

33. Davies JT, Rideal EK. Interfacial phenomena. 2nd ed. New York: Academic Press; 1963. 
34. Ross PD, Subramanian S. Thermodynamics of protein association reactions: forces contributing to stability. Biochemistry. 1981;20:3096-102.

35. Ismailos G, Reppas C, Dressman JB, Macheras P. Unusual solubility behavior of cyclosporine A in aqueous media. J Pharm Pharmacol. 1991;43:287-9.

36. Loosli HR, Oschkinat H, Weber HP, Petcher TJ, Widmer A. The conformation of cyclosporine A in the crystal and solution. Helv Chim Acta. 1985;68:682-704.

37. Hasumi H, Nishikawa T, Ohtani H. Effect of temperature on molecular structure of cyclosporine A. Biochem Mol Biol Int. 1994;34:505-11.

38. Czogalla A. Oral cyclosporine A-the current picture of its liposomal and other delivery system. Cell Mol Biol Lett. 2009;14:139-52.

39. Philippova OE, Volkov EV, Sitnikova NL, Khokhlov AR. Two types of hydrophobic aggregates in aqueous solutions of chitosan and its hydrophobic derivative. Biomacromol. 2001;2:483-90.
40. Romeu NV, Miñones J, Conde O, Iribarnegaray E, Casas M. Study of $\pi$-A curves mixed monolayers of cyclosporine and poly(DL-lactic acid-co-glycolic acid) spread at the air/water interface. J Colloid Interface Sci. 1997;185:77-83.

41. Pavinatto FJ, Pavinatto A, Caseli L, dos Santos DS Jr, Nobre TM, Zaniquelli MED, Oliveira ON Jr. Interaction of chitosan with cell membrane models at the air/water interface. Biomacromolecules. 2007;8:1633-40.

42. Pavinatto FJ, Caseli L, Pavinatto A, dos Santos DS Jr, Nobre TM, Zaniquelli MED, Silva HS, Miranda PB, Oliveira ON Jr. Probing chitosan and phospholipid interactions using Langmuir and Langmuir-Blodgett films as cell membrane models. Langmuir. 2007;23:7666-71.

Publisher's Note Springer Nature remains neutral with regard to jurisdictional claims in published maps and institutional affiliations. 